SILVA, N.F.; FERREIRA, F.A.; FONTES, P.C.R.; SEDIYAMA, M.A.N. Crescimento e estado nutricional de abóbora híbrida em função de adubação orgânica e mineral. Horticultura Brasileira, Brasília, v. 17, n. 3, p. 193-200, novembro 1999.

\title{
Crescimento e estado nutricional de abóbora híbrida em função de adu- bação orgânica e mineral ${ }^{1}$.
}

\author{
Natan F. Silva ${ }^{2}$; Francisco A. Ferreira ${ }^{3}$; Paulo C. R. Fontes ${ }^{3}$; Maria Aparecida N. Sediyama ${ }^{4}$ \\ 2/UFG Escola de Agronomia, C. Postal 131, 74.001-970 Goiânia - GO; ${ }^{3 /}$ UFV - Dep. de Fitotecnia, 36.571-000 Viçosa-MG; ${ }^{4}$ EPAMIG/ \\ UFV, 36.571-000 Viçosa - MG.
}

\section{RESUMO}

Foi conduzido um ensaio em estufa com cobertura plástica, em Viçosa, MG, com finalidade de avaliar a resposta da abóbora híbrida, cv. Tetsukabuto, a cinco doses $\left(0,25,50,100\right.$ e 150 g.dm $\left.{ }^{-3}\right)$ de composto orgânico produzido com resíduos de suínos e bagaço de cana em três níveis $(0,1$ e 2$)$ de adubação mineral (AM). No nível 1 da adubação mineral foram adicionados, em $\mathrm{mg}^{-\mathrm{dm}^{-3}}$ de substrato, os elementos: 150 de P; 50 de N; 75 de K; 20 de S; 58,5 de Ca; 14 de $\mathrm{Mg} ; 0,5$ de B; 0,5 de Cu; 1 de Zn e 0,1 de Mo. No nível 2 adicionouse o dobro das doses dos nutrientes aplicadas no nível 1 . O experimento foi em fatorial $5 \times 3$, e os tratamentos distribuídos em blocos ao acaso com quatro repetições. Cada parcela foi constituída por um vaso contendo $10 \mathrm{dm}^{3}$ de substrato, com uma planta cada. Após 36 dias da semeadura, o composto orgânico e o adubo mineral propiciaram aumentos da área foliar, da matéria seca da parte aérea das plantas e aumentos dos teores de $\mathrm{P}, \mathrm{Ke} \mathrm{S}$ e redução dos teores de $\mathrm{N}, \mathrm{Mg}$, e Ca na matéria seca do limbo foliar.

Palavras-chave: Cucurbita maxima x C. moschata, teores de nutrientes, crescimento, adubação orgânica, adubação mineral.

\section{ABSTRACT}

Nutritional state of hybrid squash as a function of organic compost and mineral fertilizer.

An experiment was carried out in a plastic greenhouse, in Viçosa, Minas Gerais, Brazil, to evaluate the response of hybrid squash $\mathrm{cv}$. Tetsukabuto to five rates $\left(0,25,50,100\right.$, and $\left.150 \mathrm{~g} / \mathrm{dm}^{3}\right)$ of organic compost combined with three levels $(0,1$ and 2$)$ of mineral fertilizer. At level 1 of mineral fertilizer the following nutrients were added in mg per $\mathrm{dm}^{3}$ of substrate: 150 of P; 50 of N; 75 of K; 20 of S; 58.5 of $\mathrm{Ca} ; 14$ of $\mathrm{Mg} ; 0.5$ of $\mathrm{B} ; 0.5$ of $\mathrm{Cu} ; 1$ of $\mathrm{Zn}$ and 0.1 of Mo. At level 2, a double of the quantities applied at level 1 were added. The experiment was laid out as a $5 \times 3$ factorial arrangement, and the treatments randomly distributed in blocks, with four repetitions. Each sample comprised a pot containing $10 \mathrm{dm}^{3}$ of substrate and a single plant. Thirty six days after planting the organic compost and mineral fertilizer resulted in increases in leaf area, dry weight of aerial parts, and $\mathrm{P}, \mathrm{K}$ and $\mathrm{S}$ content, and a decrease in the contents of $\mathrm{N}$, $\mathrm{Mg}$ and $\mathrm{Ca}$ in the dry matter of the leaf blade.

Keywords: Cucurbita maxima x C. moschata, nutrient concentration, growth, organic compost, mineral fertilizer.

(Aceito para publicação em 22 de setembro de 1999)

\footnotetext{
${ }^{1}$ Parte da tese de doutoramento do primeiro autor, apresentado à UFV, Viçosa, MG. Trabalho executado com o apoio financeiro da CAPES e FAPEMIG.
} 
$\mathrm{O}$ cultivo de abóbora híbrida cv. Tetsukabuto tem sido feito em diversas regiões produtoras do país, utilizando adubação orgânica e mineral, mas as doses ainda não estão bem estabelecidas (Makishima, 1991). No Brasil, trabalhos relatando os efeitos da adubação no crescimento e nutrição deste híbrido são, praticamente, inexistentes. Mesmo na literatura estrangeira poucos trabalhos contemplam esta planta (Fontes \& Lima, 1993).

A adubação orgânica, prática milenar de fertilização dos solos cultivados, reconhecidamente contribui para a atividade biológica e produção das culturas. Esse efeito da matéria orgânica tem sido relacionado com seu conteúdo de nutrientes e modificações nas propriedades físicas do solo, principalmente através da melhor agregação do solo, que, por sua vez, influencia na capacidade de infiltração e retenção de água, drenagem, aeração, temperatura e penetração radicular (Allison, 1973; Kang, 1991). Chen \& Aviad (1990) e Varanine et al. (1993) afirmam que a resposta de crescimento obtida na presença de matéria orgânica não pode ser explicada somente pelo seu conteúdo de nutrientes ou melhores condições físicas do solo, mas também pela melhor absorção de nutrientes.

Essa melhor absorção de nutrientes pelas plantas na presença de matéria orgânica pode ser atribuída à interações entre compostos orgânicos e a membrana plasmática das células. Varanine et al., (1993) constataram um aumento da atividade de $\mathrm{H}$-ATPases da membrana de vesículas isoladas de raízes de aveia na presença de substâncias húmicas de baixo peso molecular.

Nos solos brasileiros onde predominam minerais argilosos como a caulinita e os óxidos hidratados de ferro e alumínio, com baixo poder de troca catiônica (Moniz et al. 1995; Santos \& Batista 1996), a matéria orgânica torna-se constituinte de extrema importância na manutenção da sua fertilidade, (Kang, 1991).

Silva Jr. \& Vizzoto (1990) observaram maior rendimento e qualidade de frutos na cultura do tomateiro, quando parte dos fertilizantes minerais foi substituída pelo adubo orgânico. Kang (1993) afirma que, em solos do sul da
Nigéria, maiores produtividades de milho foram obtidas com a combinação da aplicação dos fertilizantes minerais e orgânicos. Rodrigues (1990) também relata maior produtividade de alface em função de doses de composto orgânico. No entanto, Pacheco (1996) estudando doses de composto orgânico de cana-deaçúcar e dejeto de suínos não obteve ganho de produtividade em repolho, mas observou uma redução dos teores de $\mathrm{N}$ na planta.

Na região da Zona da Mata de Minas Gerais, em razão de sua topografia acidentada, o cultivo de olerícolas é feito em pequenas propriedades e com pouca utilização de insumos. Em Ponte Nova, a suinocultura é uma atividade de relativa expressão, gerando grandes volumes de resíduos orgânicos e constituindo-se em grave problema de poluição ambiental, pois são acumulados em lagoas ou lançados diretamente nos cursos d'água. Uma alternativa seria utilizálos como fonte de matéria orgânica para os solos cultivados. Assim surgiu a necessidade de um estudo que oriente o uso racional desses resíduos, principalmente no cultivo de hortaliças, que tradicionalmente utilizam, além dos fertilizantes minerais, a adubação orgânica (Sediyama et al., 1995).

Desse modo o objetivo deste trabalho foi avaliar o crescimento e o estado nutricional da abóbora híbrida cv. Tetsukabuto, em função da adubação com doses de composto orgânico produzido com resíduos de suínos e bagaço de cana em três níveis de adubação mineral.

\section{MATERIAL E MÉTODOS}

O ensaio foi conduzido em condições de estufa com cobertura plástica, nas dependências do DFT/UFV, no Município de Viçosa, MG. Utilizaramse vasos de plástico preto, contendo 10 $\mathrm{dm}^{3}$ de substrato, preparado com amostra de um solo Podzólico VermelhoAmarelo Câmbico fase terraço, de textura argilosa, coletado na camada arável, na Estação Experimental da EPAMIG. Originalmente, esse solo apresentava as seguintes características: $\mathrm{pH}\left(\mathrm{H}_{2} \mathrm{O}\right)=5,9 ; \mathrm{P}=13,8 \mathrm{mg} / \mathrm{dm}^{3} ; \mathrm{K}=$ $66 \mathrm{mg} \cdot \mathrm{dm}^{-3} ; \mathrm{Al}=0,0 \mathrm{cmol}_{\mathrm{c} .} \mathrm{dm}^{-3} ; \mathrm{H}+\mathrm{Al}$ $=2,4 \mathrm{cmol}_{\mathrm{c}} \cdot \mathrm{dm}^{-3} ; \mathrm{Ca}=3,4 \mathrm{cmol} \cdot \mathrm{dm}^{3}$;
$\mathrm{Mg}=1,1 \mathrm{cmol}_{\mathrm{c}} \cdot \mathrm{dm}^{-3} ;$ CTC-total $=7,01$ $\mathrm{cmol}_{\mathrm{c}} \cdot \mathrm{dm}^{-3}$; saturação de bases $65,7 \%$ e carbono orgânico = 15,6 g. $\mathrm{kg}^{1}$.

Os tratamentos foram constituídos por cinco doses de um composto previamente preparado $(0,25,50,100$ e 150 g.dm ${ }^{-3}$, em base seca) e três níveis $(0,1$ e 2) de adubação mineral (AM), arranjados em esquema fatorial $5 \times 3$, com quatro repetições. $\mathrm{O}$ delineamento experimental foi blocos completos casualizados. Cada parcela foi constituída de um vaso com uma planta.

O composto utilizado foi preparado com bagaço de cana enriquecido com dejeto líquido de suínos atingindo relação $\mathrm{C} / \mathrm{N}$ inicial aproximada de 35:1, seguindo metodologia adaptada de Kielh (1985). Na confecção da pilha do composto, o bagaço de cana foi disposto em camadas de 20 a $30 \mathrm{~cm}$ e irrigado com dejeto líquido de suínos. Na operação de revolvimento, a cada três ou quatro semanas, adicionou-se mais dejeto líquido de suínos, enriquecendo e devolvendo a umidade adequada ao composto. No momento de utilização, aos 90 dias, o composto apresentava as seguintes características $\mathrm{pH}\left(\mathrm{H}_{2} \mathrm{O}\right)=6,9$; $\mathrm{N}=14,5$ g. $\mathrm{kg}^{-1} \mathrm{P}=12,4$ g. $\mathrm{kg}^{-1} ; \mathrm{K}=6,7$ g.kg ${ }^{1} ; \mathrm{Ca}=24,9$ g.kg ${ }^{1} ; \mathrm{Mg}=5,0$ g.kg 1; $\mathrm{S}=3,1 \mathrm{~g} \cdot \mathrm{kg}^{1}$; carbono orgânico = 250 g. $\mathrm{kg}^{1}$; matéria seca $=354$ g. $\mathrm{kg}^{1}$ e relação carbono/nitrogênio $=17,2$.

No nível 1 da adubação mineral, foram adicionados os seguintes elementos, por $\mathrm{dm}^{3}$ de substrato: $150 \mathrm{mg}$ de $\mathrm{P}, 50$ mg de N, $75 \mathrm{mg}$ de K, $20 \mathrm{mg}$ de S, 58,5 $\mathrm{mg}$ de $\mathrm{Ca}, 14 \mathrm{mg}$ de $\mathrm{Mg}, 0,5 \mathrm{mg}$ de B, $0,5 \mathrm{mg}$ de $\mathrm{Cu}, 1 \mathrm{mg}$ de $\mathrm{Zn} \mathrm{e} 0,1 \mathrm{mg}$ de Mo, utilizando-se os sais $\mathrm{KH}_{2} \mathrm{PO}_{4}$, $\mathrm{Ca}\left(\mathrm{H}_{2} \mathrm{PO}_{4}\right) \mathrm{H}_{2} \mathrm{O},\left(\mathrm{NH}_{4}\right)_{2} \mathrm{SO}_{4}, \mathrm{NH}_{4} \mathrm{NO}_{3}$,

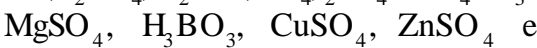
$\left(\mathrm{NH}_{4}\right)_{6} \mathrm{Mo}_{7} \mathrm{O}_{24}$. No nível 2 adicionou-se o dobro das doses dos nutrientes aplicados no nível 1. Esses nutrientes foram adicionados ao solo na forma de solução, na quantidade de $500 \mathrm{ml}$ por vaso. Nos vasos correspondentes aos tratamentos da dose 0 (zero) de adubo mineral, foram aplicados $500 \mathrm{ml}$ de água deionizada.

Foram feitas duas adubações de cobertura com uréia, em todos os vasos, inclusive no tratamento zero, aplican-

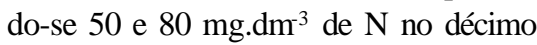
quinto e no vigésimo-quinto dia, respectivamente, após a semeadura. 
$\mathrm{Na}$ semeadura plantaram-se quatro sementes por vaso, a $1,5 \mathrm{~cm}$ de profundidade, deixando-se após os desbastes, apenas uma planta por vaso no décimo dia após a semeadura. As irrigações foram feitas, inicialmente a cada dois ou três dias aplicando-se dois ou três litros de água por vaso. Com o crescimento das plantas a frequiência e as quantidades de água aplicadas foram aumentadas de modo a atender a demanda e manter o substrato com umidade próxima da capacidade de campo.

No décimo quinto dia, antes da primeira adubação em cobertura, e no trigésimo-sexto dia após a semeadura, foram tomadas amostras de solo dos vasos, a dez centímetros da haste das plantas, para determinar a condutividade elétrica na umidade de saturação em extrato aquoso de $100 \mathrm{~g}$ de solo seco (Richards, 1954). No trigésimo-sexto dia foi feita a medida da maior largura de cada folha, para estimar a área foliar por meio de um modelo matemático previamente desenvolvido (Silva, 1997). O limbo foliar da quinta, sexta e sétima folha aberta contadas a partir do ápice foram colhidos, pesados e utilizados para a determinação do teor de nutrientes. A parte aérea das plantas foi colhida para obtenção do peso da matéria fresca e, em seguida, juntamente com as amostras dos limbos foliares, foram submetidas a secagem, em estufa a $60^{\circ} \mathrm{C}$, até peso constante, determinando-se então o peso da matéria seca. As amostras para as determinações dos teores de nutrientes foram moídas em moinho do tipo Wiley, com peneira de 20 mesh, e acondicionadas em frascos, para posterior análise. Para as análises químicas realizadas conforme metodologia empregada por Malavolta et al. (1997), as amostras foram digeridas com $\mathrm{H}_{2} \mathrm{SO}_{4} \mathrm{e}$ $\mathrm{H}_{2} \mathrm{O}_{2}$ para determinação dos teores de $\mathrm{N}$ pelo reagente de Nessler, e com ácido nitro-perclórico, para as determinações de $\mathrm{P}$ por colorimetria, $\mathrm{K}$ por fotometria de chama, $\mathrm{S}$ por turbidimetria e $\mathrm{Ca}$ e $\mathrm{Mg}$ por espectrofotometria de chama de absorção atômica.

\section{RESULTADOS E DISCUSSÃO}

A Tabela 1 apresenta as equações de regressão com os respectivos coeficien-

Tabela 1. Equações de regressão, aos 15 dias após a semeadura, da condutividade elétrica dos substratos, e aos 36 dias após a semeadura, da condutividade elétrica dos substratos, da área foliar e do peso da matéria seca da parte aérea, em função do composto orgânico e da adubação mineral (AM) em três níveis (0, 1 e 2). Viçosa (MG), UFV, 1997.

\begin{tabular}{|c|c|c|}
\hline Niveis de AM & Equaçăo de Regressāo & $\mathbf{R}^{2}$ \\
\hline \multicolumn{3}{|c|}{ Condutividade olétrica dos substratos aos 15 dias após a semeadura } \\
\hline 0 & $\hat{Y}=0,22+0,0165^{\circ 1} X$ & 0,86 \\
\hline 1 & $\hat{Y}=2,41+0,01.34^{\prime \prime} X$ & 0.92 \\
\hline 2 & $\hat{Y}=4,04+0,0114^{\prime \prime} X$ & 0,89 \\
\hline \multicolumn{3}{|c|}{ Condutividade elétrica dos substratos aos 36 dias após a semeadura } \\
\hline 0 & $\hat{\gamma}=0,95-0,123^{\prime \prime} \sqrt{X}+0,0135^{\prime \prime} X$ & 0,91 \\
\hline 1 & $Y=0,41+0,00559^{\circ} x$ & 0,90 \\
\hline 2 & $\hat{y}=00,61)-0,00161 x+0,0000571^{2} x^{2}$ & 0,98 \\
\hline \multicolumn{3}{|c|}{ Área foliar ( $\mathrm{cm}^{2} /$ planta) } \\
\hline 0 & $Y=1.991,5 i+1,038,52^{\prime \prime} \sqrt{X} \quad 47,11 S^{\prime \prime} X$ & 0.98 \\
\hline 1 & $\hat{Y}=6.597,37,14,842^{*} X$ & 0,86 \\
\hline 2 & $\hat{Y}-7,728,37+18,782^{4} X$ & 0,94 \\
\hline \multicolumn{3}{|c|}{ Peso da matéria seca da parte aérea (g/planta) } \\
\hline 0 & $\hat{Y}=14,47+1,029^{+4} X-0,000525^{-1} X^{2}$ & 0.99 \\
\hline 1 & $\hat{Y}=42,90+0,329^{*} X-0,00155^{* *} X^{2}$ & 0.96 \\
\hline 2 & $\hat{Y}=54,43+0,1148^{41} X$ & 0,98 \\
\hline
\end{tabular}

*** Significativos a 5 e $1 \%$ de probabilidade, respectivamente pelo teste $\mathrm{t}$.

tes de determinação $\left(\mathrm{R}^{2}\right)$ da condutividade elétrica dos substratos aos 15 dias e aos 36 dias após a semeadura, da área foliar e do peso da matéria seca da parte aérea.

Observou-se efeito significativo da interação AM x Composto na área foliar. O desdobramento da interação mostrou que no nível zero da AM, o efeito da dose de composto orgânico sobre a área foliar seguiu o modelo quadrático base raiz quadrada, e, nas doses 1 e 2, modelos lineares positivos (Tabela 1). $\mathrm{Na}$ ausência de AM as doses iniciais (25 e $50 \mathrm{~g} \cdot \mathrm{dm}^{3}$ ) de composto, além de contribuir com as propriedades físicas do solo, parecem ter suprido boa parte dos nutrientes propiciando um aumento significativo da área foliar que foi crescente até a dose de 121 g.dm ${ }^{3}$, quando atingiu o máximo de $7.714 \mathrm{~cm}^{2}$.planta ${ }^{-1}$ (Tabela 2). Doses maiores que 121 g.dm ${ }^{3}$ de composto orgânico reduziram a área foliar, provavelmente devido a imobilização de $\mathrm{N}$, que nesse caso não foi suprido pela AM. A imobilização do N pode ser atribuída à composição fibrosa do bagaço de cana-de-açúcar no composto, concordando com o encontrado por Pacheco (1996).
Na característica peso da matéria seca da parte aérea constatou-se a existência de interação entre AM e composto. Nos níveis 0 e 1 da adubação mineral, a resposta do peso da matéria seca às doses de composto seguiu o modelo quadrático, e, no nível 2 , a resposta foi linear positiva (Tabela 1). Esse efeito quadrático, observado nos níveis 0 e 1 da AM, pode ser explicado pela contribuição significativa do composto, principalmente nas doses menores, na absorção de $\mathrm{P}, \mathrm{K}$ e S pelas plantas e, nas maiores, pela imobilização do $\mathrm{N}$ que reduziu os teores na planta. Nota-se que o composto orgânico sozinho é capaz de explicar a maior parte do crescimento das plantas em matéria seca. $\mathrm{O}$ efeito positivo da matéria orgânica no crescimento de plantas tem sido relacionado com o aumento da absorção de nutrientes minerais, sendo relatados na literatura efeitos no crescimento, tanto de raízes como da parte aérea (Rauthan \& Schnitzer, 1981; Chen \& Aviad, 1990; Varanine et al., 1993; Vidigal et al., 1997).

Considerando que em geral a máxima eficiência econômica situa-se um pouco abaixo do ponto de máximo, estimaram-se por meio das equações de 
Tabela 2. Valores estimados, aos quinze dias após a semeadura da condutividade elétrica e aos 36 dias após a semeadura, da condutividade elétrica, área foliar, peso da parte aérea seca e correspondentes doses do composto orgânico, nos pontos de máximo, 95\% e 90\% do máximo daquelas características, em três níveis de adubação mineral. Viçosa (MG), UFV, 1997.

\begin{tabular}{|c|c|c|c|c|c|c|}
\hline \multirow{2}{*}{$\begin{array}{c}\text { Nível de } \\
\text { Adubação } \\
\text { Mineral }\end{array}$} & \multicolumn{3}{|c|}{ Valores estimados } & \multicolumn{3}{|c|}{ Doses do composto } \\
\hline & Máximo & $95 \%$ & $90 \%$ & Máximo & $95 \%$ & $90 \%$ \\
\hline & \multicolumn{3}{|c|}{ Condutividade elétrica aos quinze dias (dS.m $\left.\mathrm{m}^{-1}\right)$} & \multicolumn{3}{|c|}{ g.dm ${ }^{-3}$} \\
\hline 0 & 2,7 & 2,6 & 2,4 & 150 & 144 & 132 \\
\hline 1 & 4,4 & 4,2 & 4,0 & 150 & 133 & 119 \\
\hline \multirow[t]{2}{*}{2} & 5,8 & 5,5 & 5,2 & 150 & 128 & 102 \\
\hline & \multicolumn{3}{|c|}{ Condutividade elétrica aos 36 dias (dS. $\left.\mathrm{m}^{-1}\right)$} & \multicolumn{3}{|c|}{ g.dm $m^{-3}$} \\
\hline 0 & 1,5 & 1,4 & 1,3 & 150 & 142 & 130 \\
\hline 1 & 1,2 & 1,1 & 1,1 & 150 & 123 & 123 \\
\hline \multirow[t]{2}{*}{2} & 1,6 & 1,5 & 1,4 & 150 & 140 & 133 \\
\hline & \multicolumn{3}{|c|}{ Área foliar por planta $\left(\mathrm{cm}^{2}\right)$} & \multicolumn{3}{|c|}{ g.dm $m^{-3}$} \\
\hline 0 & 7.714 & 7.328 & 6.943 & 121 & 67 & 49 \\
\hline 1 & 8.824 & 8.383 & 7.941 & 150 & 120 & 90 \\
\hline \multirow[t]{2}{*}{2} & 10.546 & 10.019 & 9.491 & 150 & 122 & 94 \\
\hline & \multicolumn{3}{|c|}{ Peso da parte aérea seca (g.planta ${ }^{-1}$ ) } & \multicolumn{3}{|c|}{ g. $\mathrm{dm}^{-3}$} \\
\hline 0 & 64,9 & 61,6 & 58,4 & 98 & 73 & 63 \\
\hline 1 & 60,4 & 57,4 & 54,3 & 106 & 62 & 44 \\
\hline 2 & 71,6 & 68,0 & 64,5 & 150 & 118 & 85 \\
\hline
\end{tabular}

regressão, além do ponto de máximo, os valores das características a 95 e a $90 \%$ do máximo e as respectivas doses do composto (Tabela 2). Para as funções lineares crescentes considerou-se, como ponto de máximo, a maior dose de composto utilizada (150 g. $\left.\mathrm{dm}^{-3}\right)$.

A análise estatística dos dados de condutividade elétrica (CE) dos extratos dos substratos, medida aos quinze e aos 36 dias após a semeadura, mostrou efeitos significativos, apenas para os fatores isolados composto orgânico e adubo mineral. A CE aos 15 dias após a semeadura cresceu linearmente em função das doses de composto orgânico nos três níveis da adubação mineral (Tabela 1). Através das equações estimaram-se os pontos de máximo da CE nos níveis 0,1 e 2 da AM que foram, respectivamente, $2,7,4,4$ e $5,8 \mathrm{dS} . \mathrm{m}^{-1}$ correspondentes à dose de $150 \mathrm{~g} / \mathrm{dm}^{3}$ de composto (Tabela 2).

Aos 36 dias após a semeadura a resposta de CE às doses de composto orgânico foi quadrática base raiz quadrada no nível 0 , linear no nível 1 e quadrática no nível 2 da AM (Tabela 1). Nessa época os valores máximos esti- mados de CE (Tabela 2) foram menores que $3 \mathrm{dS} . \mathrm{m}^{-1}$, que indica baixa salinidade. Nas doses 0,25 e 50 g.dm ${ }^{3}$ de composto do nível zero da AM o crescimento quadrático positivo em matéria seca da parte aérea, provavelmente exigiu absorção de mais nutrientes e reduziu os teores de sais do substrato correspondendo um decréscimo quadrático da $\mathrm{CE}$.

Os valores de $\mathrm{CE}$ aos 36 dias da semeadura, menores que aos dos 15 dias, podem ser explicados pela absorção em função do crescimento das plantas, e possivelmente de lixiviação, atingindo no final do experimento, aos 36 dias após a semeadura, valores menores que 3 dS.m-1 (Tabela 2).

Nota-se que aos 15 dias após a semeadura, os níveis 1 e 2 do adubo mineral associados às doses maiores de composto elevaram a $\mathrm{CE}$ a valores acima de $4 \mathrm{dS} \cdot \mathrm{m}^{-1}$, (Tabela 2). Estes valores indicam níveis de salinidade que podem ser prejudiciais para a nutrição e o crescimento das plantas, podendo, de acordo com os sais envolvidos, alterar os teores de $\mathrm{K}$, Ca e Mg nas plantas e, ou, o crescimento em resposta ao estresse salino (Marschner, 1995). Rodrigues (1990), trabalhando com composto de palha de milho e esterco de bovinos, também, observou CEs bem acima de $4 \mathrm{dS} \cdot \mathrm{m}^{-1}$ nas doses maiores de adubação orgânica e mineral.

A análise dos dados de teor de $\mathrm{N}$ na matéria seca do limbo foliar mostrou efeito significativo dos fatores composto orgânico e AM com ausência de interação. $\mathrm{Na}$ dose 0 da AM, o teor de $\mathrm{N}$ seguiu o modelo quadrático base raiz quadrada, decrescendo de $39,75 \mathrm{~g} . \mathrm{kg}^{1}$ de $\mathrm{N}$ até atingir o ponto de mínimo, 30,36 g. $\mathrm{kg}^{1}$ de $\mathrm{N}$, com a dose de 76 g.dm ${ }^{-3}$ de composto (Figura 1). Na dose 1 da AM, o teor de $\mathrm{N}$ decresceu linearmente e, na dose 2 , as doses de composto não influíram nos teores de N. Nesta situação, o $\mathrm{N}$ foi suprido pela adubação mineral com formas prontamente disponíveis. Contudo, mesmo os teores menores de $\mathrm{N}$ encontrados na matéria seca do limbo foliar, nas doses 0 e 1 da AM, ficaram dentro ou um pouco acima da faixa considerada adequada para as abóboras (30 a 35 g.kg ${ }^{1}$ de N), segundo Piggott (1986).

Os valores decrescentes do teor de $\mathrm{N}$ na folha obtidos em função das doses 
de composto parecem ser devido ao fato do bagaço de cana ser de difícil decomposição, o que torna lenta a mineralização do $\mathrm{N}$, dificultando sua disponibilidade para as plantas. Matos et al. (1995), estudando a dinâmica de decomposição de compostos orgânicos preparados com resíduos de suínos, encontraram para o composto de bagaço de cana a menor taxa de decomposição do carbono $\left(\mathrm{K}_{c}\right)$ em relação aos outros materiais estudados. Esses resultados concordam com os obtidos por Pacheco (1996), enquanto que Rodrigues (1990), trabalhando com materiais de decomposição mais fácil, encontrou teores crescentes de $\mathrm{N}$ em alface em função de doses de composto orgânico.

A análise de variância dos dados de teor de fósforo na matéria seca do limbo foliar mostrou efeito significativo da interação entre os fatores AM e composto orgânico. O desdobramento da interação, apresentado na Figura 2, mostrou que o teor de fósforo na matéria seca do limbo foliar, em função das doses de composto apresentou resposta quadrática positiva na dose zero de AM, indicando que o composto sozinho pode explicar o aumento do teor de $\mathrm{P}$ na folha; na dose 1 , a resposta foi linear crescente, mostrando que nesse nível de AM o composto ainda contribuiu com o aumento do teor de P na folha; na dose 2, as doses de composto não influenciaram os teores de $\mathrm{P}$ da folha. Nas doses 0 da AM e de composto (ausência de adubação de plantio), o teor de $\mathrm{P}$ estimado foi baixo, $1,80 \mathrm{~g} \cdot \mathrm{kg}^{1}$, indicando que o teor de $13,8 \mathrm{mg} . \mathrm{dm}^{-3}$ de $\mathrm{P}$ disponível encontrado nesse solo antes dos tratamentos de adubação, considerado alto pela Comissão de Fertilidade do Solo do Estado de Minas Gerais (1989), não foi suficiente para atender às necessidades nutricionais da planta; porém, com doses de composto acima de $22 \mathrm{~g} . \mathrm{dm}^{3}$, os teores estimados ficaram na faixa de 3 a 5 g. $\mathrm{kg}^{1}$, considerada por Jones Jr. et al. (1991) como adequada para as abóboras. Clough et al. (1992), estudando doses de $\mathrm{N}$ e $\mathrm{K}$ e método de irrigação em dois locais diferentes, encontraram em folhas de $C$. pepo teores de $\mathrm{P}$ variando de 5,4 a 6,5 g. $\mathrm{kg}^{-1}$ de matéria seca.

O teor de cálcio na matéria seca do limbo foliar não foi influenciado pelas

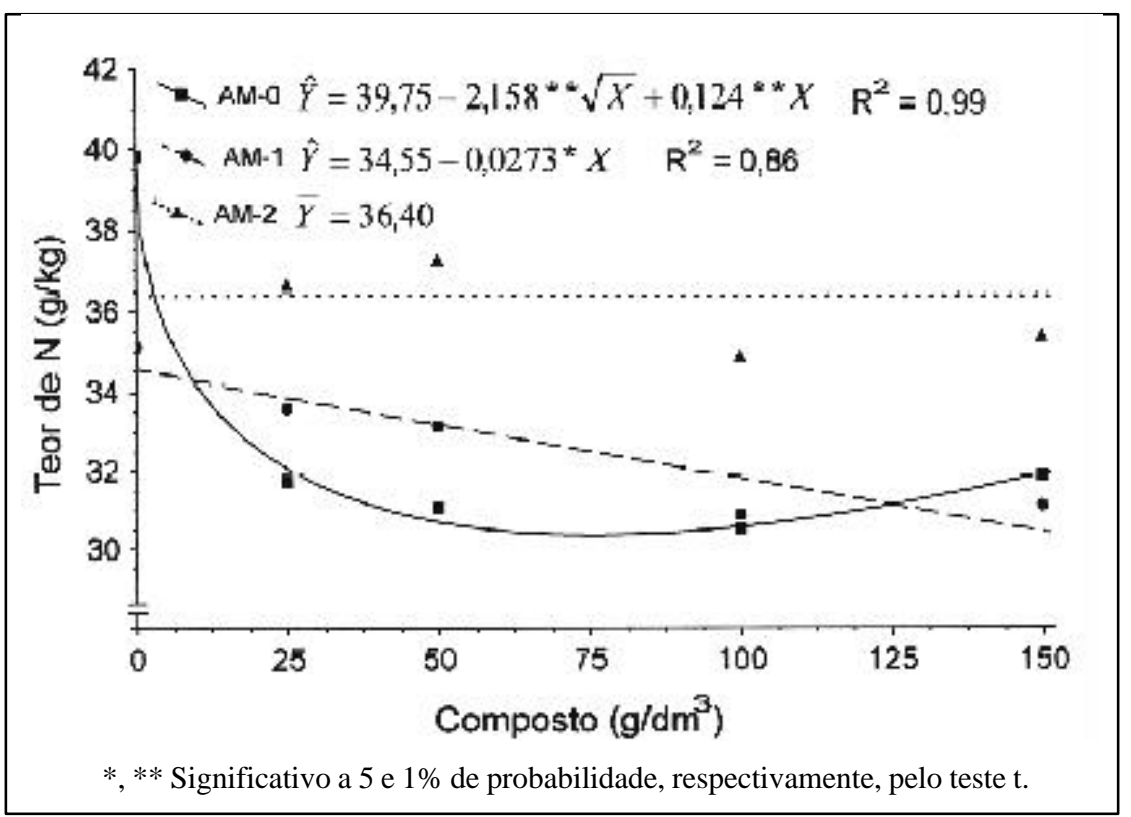

Figura 1. Teores de $\mathrm{N}$ na matéria seca do limbo da $6^{\mathrm{a}}$ folha a partir do ápice da planta de abóbora, em função do composto orgânico e da adubação mineral (AM) em três níveis $(0,1$ e 2). Viçosa (MG), UFV, 1997.

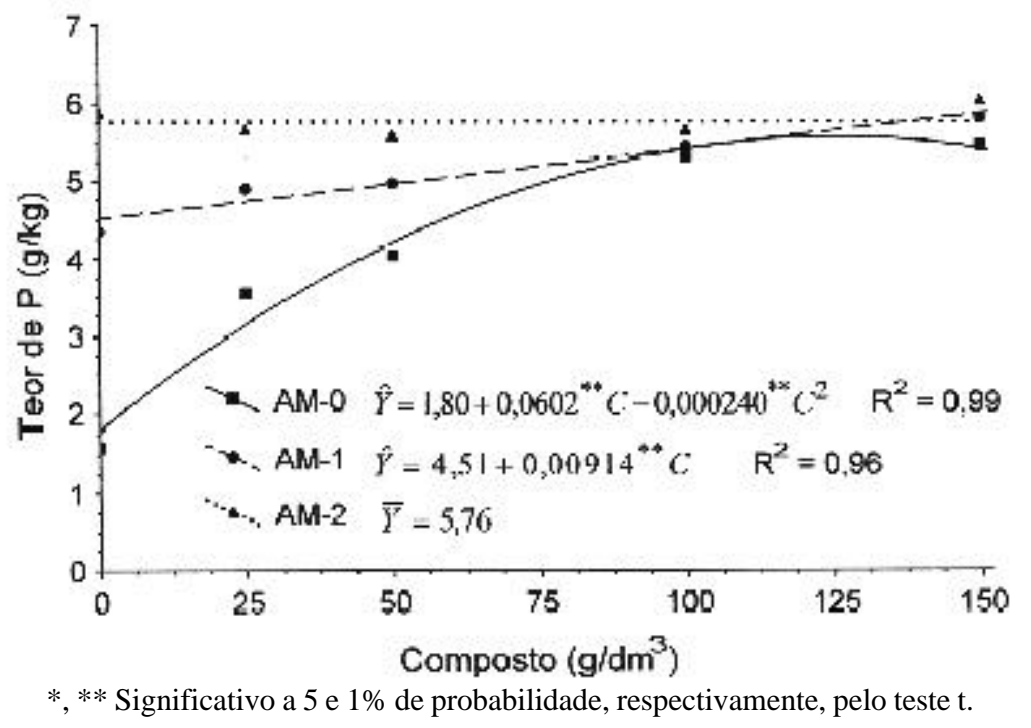

Figura 2. Teores de $\mathrm{P}$ na matéria seca do limbo da $6^{\mathrm{a}}$ folha a partir do ápice da planta de abóbora, em função do composto orgânico e da adubação mineral (AM) em três níveis $(0,1$ e 2). Viçosa (MG), UFV, 1997.

doses da AM, mas apresentaram resposta quadrática base raiz quadrada negativa em função das doses de composto, decrescendo de $20,4 \mathrm{~g} . \mathrm{kg}^{1}$ até o ponto de mínimo de 12,4 g. $\mathrm{kg}^{-1}$ na dose de 118 g.dm ${ }^{-3}$ do composto (Figura 3). Rodrigues (1990) encontrou redução do teor de $\mathrm{Ca}$ em alface pela adição de doses crescentes de composto, que foi justificada pelo desequilíbrio de sódio e potássio em relação ao cálcio; contudo, no presente trabalho o composto utilizado apresentou teor de $\mathrm{Ca}$ de 24,9 g. $\mathrm{kg}^{-1}$, ou seja, 3,7 vezes maior que o de K. É possível que esse Ca no composto estivesse em formas não prontamente disponíveis, além disso o maior crescimento da parte aérea em função do composto tenha provocado um efeito de diluição nos teores de $\mathrm{Ca}$ encontrados na 


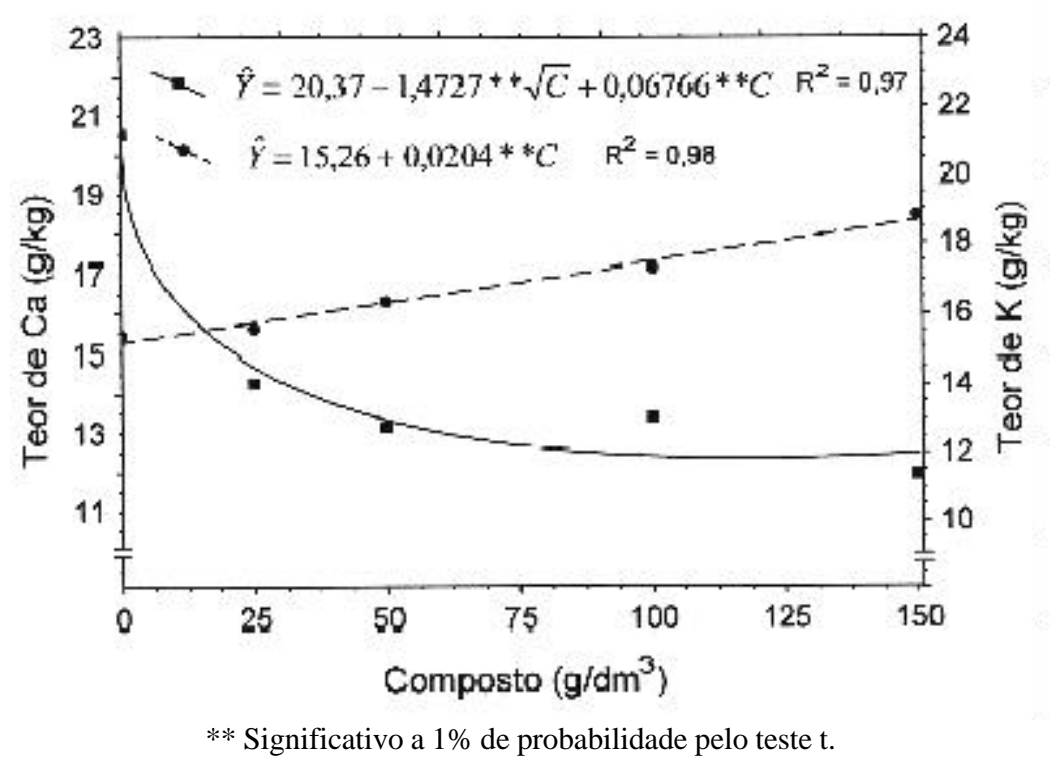

Figura 3. Teores de cálcio ( ) de potássio ( ) na mária seca do limbo da folha a partir do ápice da planta de abóbora, em função de doses de composto orgânico. Viçosa-MG, UFV, 1997.

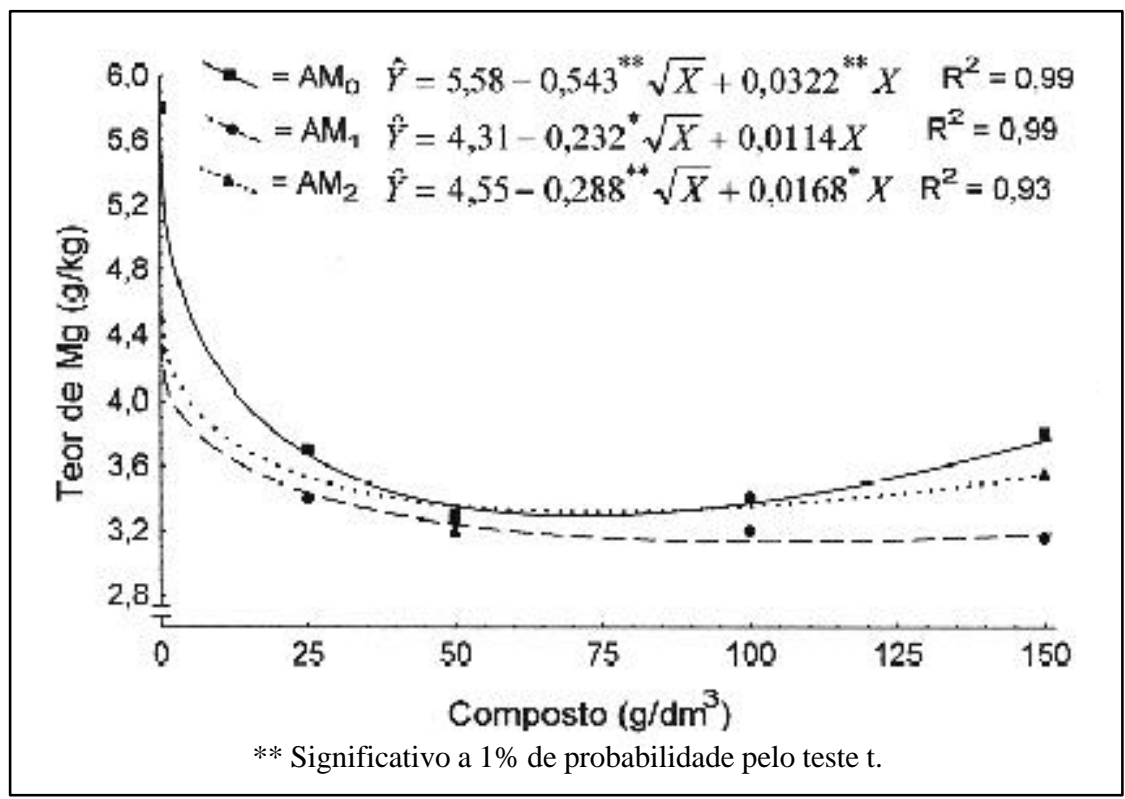

Figura 4. Teores de magnésio na matéria seca do limbo da $6^{a}$ folha a partir do ápice da planta de abóbora, em função de doses de composto orgânico. Viçosa (MG), UFV, 1997.

folha que ficaram dentro da faixa de 12 a 25 g.kg ${ }^{1}$ considerada por Jones Jr. et al. (1991) adequada para as abóboras.

A análise de variância do teor de potássio na matéria seca do limbo foliar mostrou efeito significativo apenas para as doses de composto. Na Figura 3 podese ver que os teores de $\mathrm{K}$ encontrados no limbo foliar cresceram linearmente em função das doses do composto orgânico sendo menores que a faixa de 24 a 26 g. $\mathrm{kg}^{1}$ considerada adequada para C. pepo (Piggott, 1986). Estes resultados mostram que a dose de K (150 mg.dm ${ }^{3}$ ) no nível 1 e 2 da AM, nesse solo, foi insuficiente para suprir as plantas. O composto utilizado apresentava 6,7 g.kg ${ }^{1}$ de $\mathrm{K}$ total, teor que não é alto, quando comparado com outros materiais orgânicos. Além disso é possível que parte desse $\mathrm{K}$ total estivesse disponível para as plantas. Sediyama et al. (1995) estudando diferentes composto encontraram os mais baixos teores de $\mathrm{K}$ total nos compostos preparados com bagaço de cana e dejeto líquido de suínos sendo $\mathrm{K}$ disponível apenas cerca de $40 \%$ do K total. É possível que a abóbora híbrida seja uma planta que exige teores mais altos desse nutriente. Buwalda (1986) encontrou resposta de produção por adubação potássica nesse tipo de planta em solos com $\mathrm{K}$ disponível de até $220 \mathrm{mg} \cdot \mathrm{kg}^{1}$.

A análise de variância dos dados de teor de $\mathrm{Mg}$ na matéria seca do limbo foliar mostrou efeitos das doses de composto e de AM e ausência de interação. Nas três doses da AM o teor de Mg foi melhor representado pelos modelos quadrático base raiz quadrada (Figura 4). Na dose 0 da AM, decresceu de 5,6 g. $\mathrm{kg}^{-1}$ com a dose 0 do composto até atingir o ponto de mínimo em 3,3 g.kg ${ }^{1}$ de $\mathrm{Mg}$ na dose de $71 \mathrm{~g} . \mathrm{dm}^{-3}$ do composto; na dose 1 da AM, decresceu de $4,3 \mathrm{~g} \cdot \mathrm{kg}^{1}$ com a dose 0 até o mínimo de 3,1 g.kg ${ }^{1}$ com a dose de 104 g.dm ${ }^{3}$ de composto; e, na dose 2 da AM, decresceu de $4,6 \mathrm{~g} \cdot \mathrm{kg}^{1}$ com a dose 0 até o mínimo de 3,3 g. $\mathrm{kg}^{-1}$ com a dose de 73 g. $\mathrm{dm}^{-3}$ de composto. Estes teores estão dentro da faixa considerada adequada para as abóboras, que é de 3 a 10 g.kg ${ }^{1}$ de Mg (Jones Jr. et al., 1991). As respostas decrescentes nos teores de $\mathrm{Ca} \mathrm{e}$ de $\mathrm{Mg}$ da folha podem estar relacionadas em parte com o efeito salino encontrado no composto até os 15 dias após a semeadura e em parte com o efeito de diluição pelo maior crescimento da parte aérea. Gianello \& Ernani (1983) afirmaram que, apesar dos aumentos do teor de magnésio no solo, as concentrações em plantas de milho foram decrescentes em função dos aumentos das doses de adubo orgânico, por causa da competição exercida pelo potássio, mas isso não explica os dados obtidos no presente trabalho.

Pela análise de variância constatouse interação significativa dos fatores doses do composto orgânico e adubo mineral no teor de $\mathrm{S}$ encontrado na matéria seca do limbo foliar (Figura 5). No 
nível 0 da $\mathrm{AM}$, o teor de $\mathrm{S}$ da folha foi melhor representado pelo modelo raiz quadrático, crescendo de $1,6 \mathrm{~g} \cdot \mathrm{kg}^{-1} \mathrm{com}$ a dose 0 de composto até o ponto de máximo, $2,8 \mathrm{~g} \cdot \mathrm{kg}^{-1}$, com a dose de 75 g.dm ${ }^{-3}$ de composto; nos níveis 1 e 2 da $\mathrm{AM}$, as doses do composto não influíram no teor de $\mathrm{S}$ da folha, que foram de 2,8 e 3,3 g.kg ${ }^{1}$, respectivamente. Observa-se que doses de composto acima de 50 g. $\mathrm{dm}^{-3}$ apresentaram a mesma contribuição nos teores de $\mathrm{S}$ na planta quando comparados ao nível 1 da AM. Nos solos agrícolas o $\mathrm{S}$ está presente na forma de matéria orgânica, na forma de sulfato na solução ou adsorvido no complexo sortivo do solo, mas a matéria orgânica é a principal fonte de $\mathrm{S}$, que é liberado durante a sua decomposição; adições ao solo de resíduos orgânicos pobres em $\mathrm{S}\left(<1,5 \mathrm{~g} \cdot \mathrm{kg}^{1}\right)$ conduzem à imobilização do S (Tisdale et al., 1985).

De acordo com os dados obtidos no presente trabalho, aos 36 dias da semeadura, o composto orgânico e o adubo mineral propiciaram aumentos da área foliar, da matéria seca da parte aérea e dos teores de $\mathrm{P}, \mathrm{K}$ e $\mathrm{S}$. Os teores de $\mathrm{Ca}$ e $\mathrm{Mg}$ na matéria seca do limbo foliar não foram influenciados pelas doses de adubação mineral, mas foram decrescentes com o aumento das doses de composto. Nas doses 0 e 1 da adubação mineral o composto orgânico reduziu os teores de $\mathrm{N}$ do limbo foliar. A produção máxima de matéria seca na parte aérea no nível 0 da adubação mineral, foi de 62,9 g.planta ${ }^{1}$, obtida com 95 g.dm ${ }^{3}$ (base seca) do composto e, no nível 2 , foi de 71,6 g.planta ${ }^{1}$, obtida com 150 g.dm ${ }^{3}$ do composto.

\section{LITERATURA CITADA}

ALLISON, F.E. Soil organic matter and its role in crop production. New York: Elsevier Scientific, 1973. $637 \mathrm{p}$.

BUWALDA, J.G. Hybrid squash: yield responses to potassium and phosphorus fertilisers at four sites of varying initial fertility. New Zealand of Experimental Agriculture, v. 14, p. 347-354. 1986.

CHEN, Y.; AVIAD, T. Effects of humic substances on plant growth. In: Mac CARTHY, P.; CLAPP, C.E.; MALCOLM, R.L.; BLOOM, P.R. Humic substances in soil and crop sciences: selected readings. Madison: American Society of Agronomy, Soil Science Society of America, 1990. p. 161- 186.

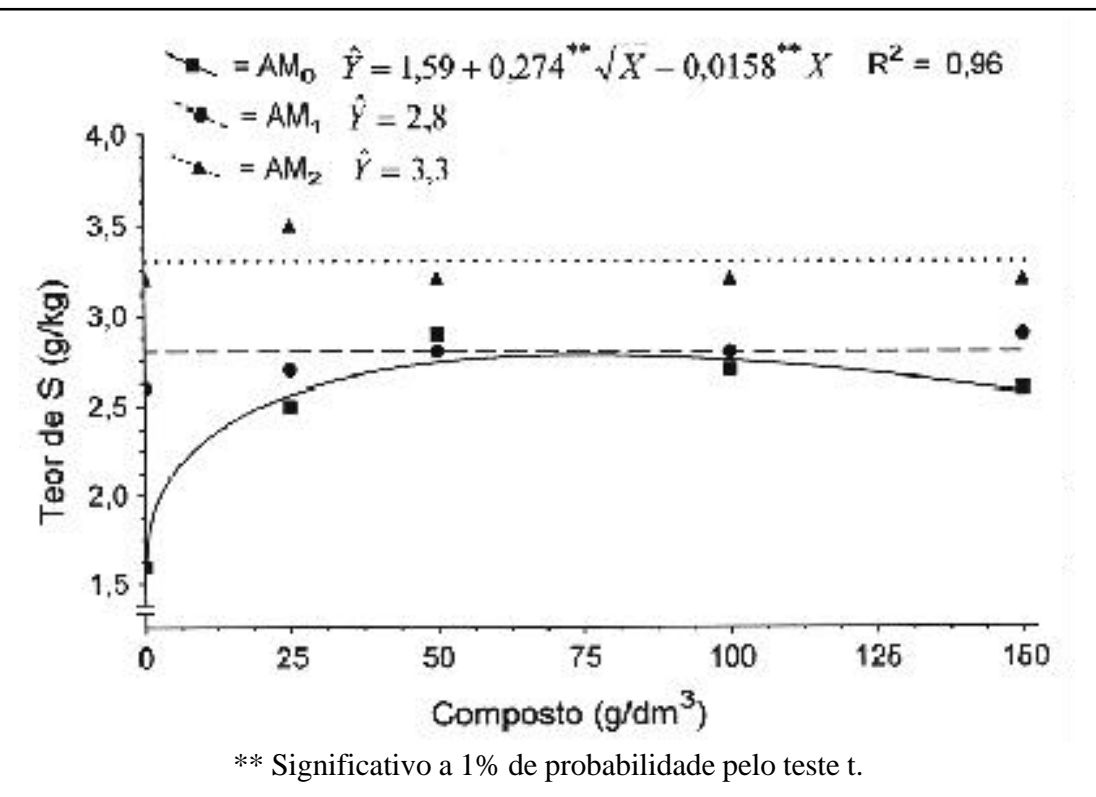

Figura 5. Teores de enxofre na matéria seca do limbo da $6^{a}$ folha a partir do ápice da planta de abóbora, em função do composto orgânico e da adubação mineral (AM) em três níveis ( 0 , 1 e 2). Viçosa (MG), UFV, 1997.

CLOUGH, G.H.; LOCASCIO, S.J.; OLSON, S.M. Mineral concentration of yellow squash responds to irrigation method and fertilization management. Journal American Society for Horticultural Science, v. 117, n. 5, p. 725729. 1992.

COMISSÃO DE FERTILIDADE DO SOLO DO ESTADO DE MINAS GERAIS. Recomendação do uso de corretivos e fertilizantes em Minas Gerais. 4a aproximação. Lavras; MG: 1989. 159 p.

FONTES, R.R.; LIMA, J. de A. Nutrição mineral e adubação do pepino e da abóbora. In: FERREIRA, M.E., CASTELLANE, P.D.; CRUZ, M.C.P. da. (Ed.). Nutrição e adubação de hortaliças. Piracicaba: Associação Brasileira para Pesquisa da Potassa e do Fosfato, 1993. p. 281-300.

GIANELLO, C.; ERNANI, P.R. Rendimento de matéria seca de milho e alterações na composição química do solo pela incorporação de quantidades crescentes de cama de frangos, em casa de vegetação. Revista Brasileira de Ciência do Solo Campinas, v. 7, p. 285 - 90, 1983.

JONES JR., J.B.; WOLF, B.; MILLS, H.A. Plant analysis handbook. Athens: Micro - Macro, 1991. $213 \mathrm{p}$

KANG, B.T. Changes in soil chemical properties and crop performance with continuos cropping on an Entisol in the humid tropics. in: MULONGOY, K.; MERCKX, R. ed. Soil organic matter dynamics and sustainability of tropical agriculture. New York: John Wiley \& Sons, 1991. p. 297 - 305.

KIEHL, E.J. Fertilizantes orgânicos. São Paulo: Agronômica Ceres, 1985. 429 p.

MAKISHIMA, N. Situação das cucurbitáceas no Brasil. Horticultura brasileira, Brasília, v. 9, n. 2, p. 99 - 101, 1991
MALAVOLTA, E.; VITTI, G.C.; OLIVEIRA, S.A. de. Avaliação do estado nutricional das plantas: princípios e aplicações. 2 ed. Piracicaba: Associação Brasileira para Pesquisa da Potassa e do Fosfato, 1997. 319 p.

MARSCHNER, H Mineral nutrition of higher plants. 2 ed. London: Academic Press, 1995 $889 \mathrm{p}$.

MATOS, A.T. de; SEDIYAMA, M.A.N.; VIDIGAL, S.M.; GARCIA, N. .P.; RIBEIRO, M.F. Compostos orgânicos contendo dejeto líquido de suínos como fonte de nitrogênio. I Dinâmica da compostagem. In: CONGRESSO BRASILEIRO DE CIÊNCIA DO SOLO, 25, 1995, Viçosa, MG, Resumos expandidos... Viçosa, MG: SBCS, UFV, 1995. p. 663 - 665.

MONIZ, A.C.; OLIVEIRA, J.B.; CURI, N. Mineralogia da fração argila de rochas sedimentares e de solos da folha de Piracicaba, SP. Revista brasileira de Ciência do Solo, Campinas, v. 19, p. 375-385, 1995.

PACHECO, D.D. Índices de disponibilidade de nitrogênio, teores de nitrato e de vitamina $C$, composição mineral e produção de repolho em resposta a doses de nitrogênio, de composto orgânico e de molibdênio. Viçosa, UFV, 1996. 79 p. (Tese mestrado).

PIGGOTT, T.J. Vegetable crops. In: REUTER D.J.; ROBINSON, J.B. ed. Plant analysis: an interpretation manual. Sydney: Inkata Press, 1986. p. 146 - 187.

RAUTHAN, B.S.; SCHNITZER. Effects of soil fulvic acid on the growth and nutrient content of cucumber (Cucumis sativus) plants. Plant and Soil, v. 63, p. 491 - 495, 1981.

RICHARDS, L.A. Diagnóstico y rehabilitacion de suelos salinos y sodicos. México: L.A. Richards editor, Centro Regional de Ayuda Tecnica, 1954. $172 \mathrm{p}$. 
RODRIGUES, E.T. Efeitos das adubações orgânica e mineral sobre o acúmulo de nutrientes e sobre o crescimento da alface (Lactuca sativa L.). Viçosa, UFV, 1990. 60 p. (Tese mestrado).

SANTOS, M.C. dos; BATISTA, M. de A. Avaliações física, química e mineralógica em solos plínticos da região Meio-Norte do Brasil, submetidos a teste de umidecimento e secagem. Revista brasileira de Ciência do Solo, Campinas, v. 20, p. 21-31, 1996.

SEDIYAMA, M.A.N.; GARCIA, N.C.P.; VIDIGAL, S.M.; MATOS, A.T. de M.; LOURES, E.G. Compostos orgânicos contendo dejeto líquido de suínos como fonte de nitrogênio: II. Valor fertilizante dos compostos. In: CONGRESSO BRASILEIRO DE CIÊNCIA DO SOLO, 25, 1995, Viçosa, MG, Resumos expandido $\mathrm{s} .$. Viçosa, MG: SBCS, UFV, 1995. p. $666-668$
SILVA JR., A.A.; VIZZOTTO, V.J. Efeito da adubação mineral e orgânica sobre a produtividade e tamanho de fruto de tomate. Horticultura brasileira, Brasília, v. 8, p. 17-19, 1990.

SILVA, N.F. da. Crescimento, nutrição e produção da abóbora híbrida, em função de adubação mineral e orgânica. Viçosa, UFV, 1997. 131 p. (Tese doutorado).

TISDALE, S.L.; NELSON, W.L.; BEATON, J.D. Soil fertility and fertilizers. 4 ed. New York: Macmillan, 1985. 754 p.

VARANINE, Z.; PINTON, R.; BIASE, M.G.; ASTOLFI, S.; MAGGIONI, A. Low molecular weight humic substances stimulate $\mathrm{H}^{+}$-ATPase activity of plasma membrane vesicles isolated from oat (Avena sativa L.) roots. Plant and Soil, v. 153, p. 61-69, 1993.
VIDIGAL, S.M.; SEDIYAMA, M.A.N.; GARCIA, N.C.P.; MATOS, A.T. de. Produção de alface cultivada com diferentes compostos orgânicos e dejetos suínos. Horticultura brasileira, Brasília, v. 15, n. 1, p. 35-39, 1997. 